\title{
Acute Myocardial Infarction in the Brazilian State of São Paulo. In-hospital Deaths from 1979 to 1996 and Hospital Fatality from 1984 to 1998 in the Public Health System
}

\author{
Luiz Francisco Marcopito, A rtur Jaques Goldfeder, Simone Schenkman
}

São Paulo, SP - Brazil

\begin{abstract}
Objective - To determine the following parameters in the Brazilian State of São Paulo: 1) the percentage of deaths due to acute myocardial infarction (AMI) occurring in hospitals; 2) the percentage of deaths due to AMI occurring in public health system hospitals as compared with all in-hospital deaths due to AMI between 1979 and 1996; 3 ) the fatality due to AMI in public health system hospitals from 1984 to 1998.
\end{abstract}

Methods - Data were available on the Datasus Web site (the health information agency of the Brazilian Department of Health) that provided the following: a) number of deaths resulting from AMI in hospitals; $b$ ) number of deaths resulting from AMI in public health system hospitals; c) number of hospital admissions due to AMI in public health system hospitals.

Results - The percentage of in-hospital deaths due to AMI increased from 54.9 in 1979 to 68.6 in 1996. The percentage contribution of the public health system to total number of deaths due to AMI occurring in hospitals decreased from 22.9 in 1984 to 13.7 in 1996; fatality due to AMI occurring in public health system hospitals had an irregular evolution from 1984 to 1992 and showed a slight trend for increased frequency from 1993 to 1998.

Conclusion - The percentage of in-hospital deaths due to AMI has been increasing. Deaths resulting from AMI in public health system hospitals have decreased when compared with the total number of deaths due to AMI in all hospitals. Fatality due to AMI in public health system hospitals did not decrease from 1992 to 1998.

Key words: acute myocardial infarction, ischemic heart disease, mortality, epidemiology

Escola Paulista de Medicina - UNIFESP and Divisão de Doenças Crônicas NãoTransmissíveis, Centro de Vigilância Epidemiológica "Prof. Alexandre Vranjac", Secretaria de Estado da Saúde de São Paulo

Mailing address: Luiz F. Marcopito - Rua Pedro de Toledo, 675 - 04039-032 São Paulo, SP - Brazil.

Received on 2/4/99

Accepted on $9 / 8 / 99$
Decrease in the mortality rate due to acute myocardial infarction (AMI) observed in the Brazilian State of São Paulo ${ }^{1}$ has followed the trend of the western world ${ }^{2}$. Whether this results from a reduction in the incidence of the disease, or in the fatality rate, or from a combination of these ${ }^{3}$ is still a controversial matter. Reduction in fatality, however, in patients with AMI who arrive at hospitals has been highlighted in some parts of the world and attributed to the most recent pharmacological treatments ${ }^{4-10}$.

This study aims to assess fatality due to AMI in the Brazilian State of São Paulo by determining the following: a) whether, during the period of the study, a change in the percentage of in-hospital deaths due to AMI occurred; b) the percentage participation of the public health system hospitals in in-hospital deaths due to AMI; c) fatality due to AMI in public health system hospitals.

\section{Methods}

This study analyzed historical data gathered from the following secondary data sources: a) death certificates - in the state of São Paulo, this coverage is close to $100 \%$; b) the quality of the information on the cause of death - in the state of São Paulo, deaths resulting from ill-defined causes represented only $6 \%$ in the period from 1979 to $1996^{12}$; c) access to a database - data, even though originating from different sources (SIH [Hospital Information System] and SIM [System of Information on Mortality]), were all available at one electronic address, Datasus (the health information agency of the Brazilian Health Department $)^{12}$; and d) codification of AMI - for statistical purposes, AMI continues to be classified according to just one code, both by the $9^{\text {th }}$ and $10^{\text {th }}$ reviews of the International Classification of Diseases ${ }^{13,14}$.

We determined the following parameters for both sexes and all ages: a) the percentage of in-hospital deaths due to AMI occurring from 1979 to 1996 ; b) the percentage of deaths due to AMI in public health system hospitals based 
on all deaths due to AMI occurring in hospitals from 1984 to 1996; c) hospital fatality due to AMI occurring in the public health system from 1984 to 1998 , defined as the percentage of deaths in relation to the total number of hospital admissions due to AMI in the public health system. The periods of time differ only because of a problem in data availability. The private hospital system and the HMO system were not included in the study because of lack of official statistics.

The variables that generated this information, grouped by calendar year and the usual dwelling place of the patient/dead person, were the following: a) location of death - item number 10 on the death certificate ${ }^{15}$ or the "site of occurrence" was indicated by one of the following options: 1-) in-hospital; 2- on the street; 3- at home; 4other locations; 0- location not provided; 9- location unknown; b) deaths due to AMI in public health system hospitals; c) hospital admissions due to AMI in the public health system.

\section{Results}

The percentage of in-hospital deaths due to AMI progressively and consistently increased during the period from 1979 to 1996 (from $54.9 \%$ to $68.6 \%$ ) while a concomitant decrease in the percentage of deaths occurring at home place was observed (table I and fig. 1).

Among all in-hospital deaths due to AMI from 1984 to 1996, those deaths occurring in public health system hospitals decreased from $22.9 \%$ to $13.7 \%$ (table II and fig. 2).

Hospital fatality due to AMI in the public health system showed an irregular behavior in the period of the study. A significant increase occurred from 1984 to 1988, a decrease occurred from 1989 to 1992, and a new and slower increase occurred from 1993 to 1998 (table III and fig. 2). We can say that a reduction in hospital fatality due to AMI in the public health system did not occur in this latter period.

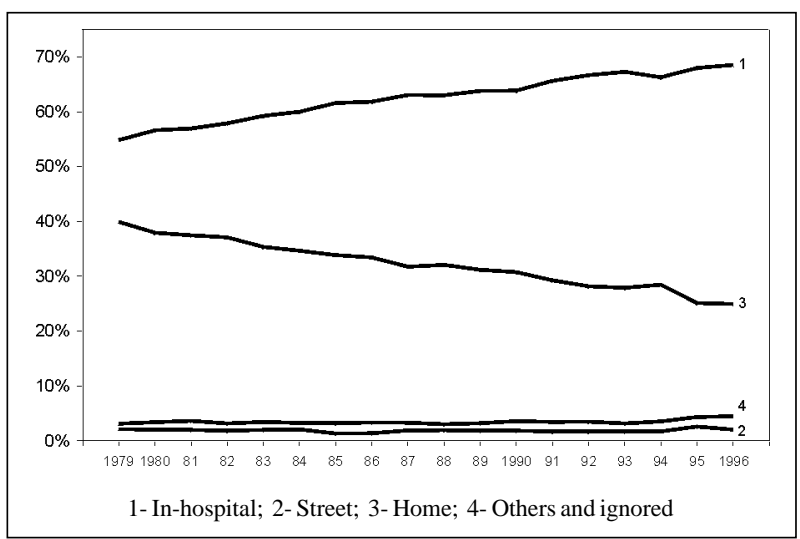

Fig. 1 - Relative distribution (\%) of the locations of death occurrence due to AMI according to the calendar year 1979 to 1996 in the state of São Paulo.

\section{Discussion}

In the literature, there is a classic observation published in 1982 in the United States that $50 \%$ of the deaths due to AMI occurres prior to the patient's arrival at the hospital ${ }^{16}$. As observed, in 1979 in the state of São Paulo, only $54.9 \%$ of the deaths due to AMI occurred in the hospital. Since then, a progressive increase in the percentage of in-hospital deaths due to AMI has occurred, reaching 68.6\% in 1996.

This increase may have resulted from improvement in patients' access to hospitals. However, we cannot ignore the possibility of a reduction in the number of fulminant cases, allowing a higher number of patients to reach the hospital before dying and to receive more modern treatments whenever available. Unfortunately, the total number of patients who benefited from the earlier hospital arrival could not be determined for the hospital network as a whole, due to lack of data outside the public health system.

Table I - Absolute distribution of the locations of death occurrence due to acute myocardial infarction (AMI) and percentage (\%) of in-hospital deaths due to AMI according to the calendar year in the state of São Paulo from 1979 to 1996

\begin{tabular}{|c|c|c|c|c|c|c|c|}
\hline \multirow[b]{2}{*}{ Year } & \multicolumn{5}{|c|}{ Location of death occurrence } & \multirow[b]{2}{*}{ Total } & \multirow[b]{2}{*}{ In-hospital $\%$} \\
\hline & Hospital & Street & Home & Others & Ignored & & \\
\hline 1980 & 7044 & 251 & 4718 & 398 & 24 & 12435 & 56.6 \\
\hline 1981 & 7150 & 248 & 4706 & 431 & 21 & 12556 & 56.9 \\
\hline 1982 & 7109 & 225 & 4556 & 382 & 5 & 12277 & 57.9 \\
\hline 1983 & 7693 & 256 & 4589 & 430 & 13 & 12981 & 59.3 \\
\hline 1984 & 7888 & 273 & 4555 & 421 & 6 & 13143 & 60.0 \\
\hline 1985 & 8307 & 180 & 4566 & 408 & 25 & 13486 & 61.6 \\
\hline 1986 & 8549 & 189 & 4623 & 452 & 10 & 13823 & 61.8 \\
\hline 1987 & 9164 & 272 & 4616 & 466 & 12 & 14530 & 63.1 \\
\hline 1988 & 9842 & 300 & 5009 & 450 & 16 & 15617 & 63.0 \\
\hline 1989 & 9972 & 288 & 4871 & 474 & 24 & 15629 & 63.8 \\
\hline 1990 & 10025 & 285 & 4832 & 510 & 48 & 15700 & 63.9 \\
\hline 1991 & 10258 & 263 & 4572 & 493 & 43 & 15629 & 65.6 \\
\hline 1993 & 10766 & 268 & 4462 & 499 & 3 & 15998 & 67.3 \\
\hline 1994 & 10873 & 278 & 4664 & 571 & 6 & 16392 & 66.3 \\
\hline 1995 & 11265 & 426 & 4162 & 671 & 44 & 16568 & 68.0 \\
\hline 1996 & 12231 & 360 & 4453 & 729 & 69 & 17842 & 68.6 \\
\hline
\end{tabular}




\begin{tabular}{|c|c|c|c|}
\hline Year & $\begin{array}{l}\text { Number of deaths due to AMI occurring } \\
\text { in public health system hospitals }\end{array}$ & $\begin{array}{l}\text { Total number of in hospital } \\
\text { deaths due to AMI }\end{array}$ & $\begin{array}{l}\text { Percentage of deaths due to AMI occurring in public health } \\
\text { system hospitals in relation to all in hospital deaths due to AMI }\end{array}$ \\
\hline 1984 & 1805 & 7888 & 22.9 \\
\hline 1985 & 1728 & 8307 & 20.8 \\
\hline 1986 & 1644 & 8549 & 19.2 \\
\hline 1987 & 1827 & 9164 & 19.9 \\
\hline 1988 & 2175 & 9842 & 22.1 \\
\hline 1989 & 2171 & 9972 & 21.8 \\
\hline 1990 & 1985 & 10025 & 19.8 \\
\hline 1991 & 2137 & 10258 & 20.8 \\
\hline 1992 & 2075 & 10452 & 19.9 \\
\hline 1993 & 2083 & 10766 & 19.3 \\
\hline 1994 & 1969 & 10873 & 18.1 \\
\hline 1995 & 1809 & 11265 & 16.1 \\
\hline 1996 & 1675 & 12231 & 13.7 \\
\hline
\end{tabular}

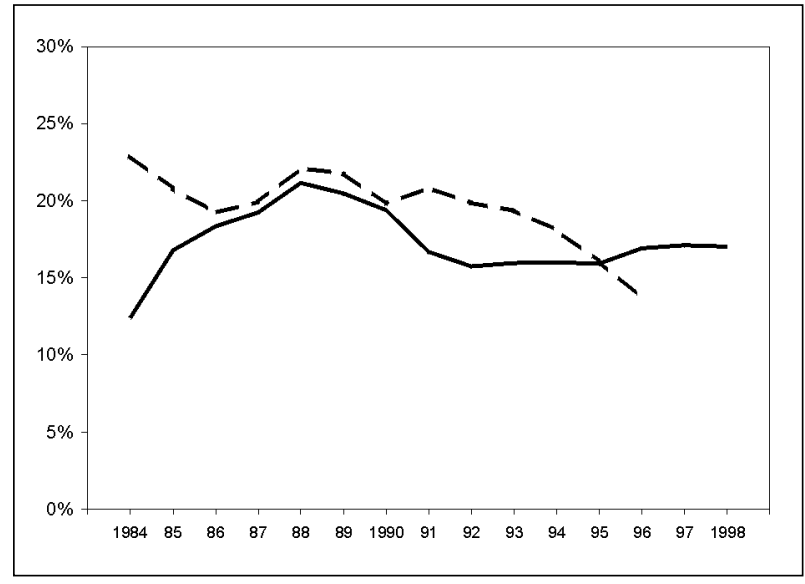

Fig. 2 - Percentage of deaths due to AMI in public health system hospitals in relation to the total of in-hospital deaths due to AMI from 1984 to 1996 (dotted line), and hospital fatality (\%) due to AMI in the public health system from 1984 to 1998 (continuous line), according to the calendar year in the state of São Paulo.
This lack of information outside the public health system could be solved if all CAH-106 (Hospital Assistance Coordination) reports, which all hospitals in the state of São Paulo have to complete, were processed. This report comprises all diagnoses at hospital admission and discharge, independently of the category of payment (private, HMO or public health system). This information would be very useful to elucidate the reasons interfering with the reduction in the mortality rate due to AMI in the population of the state of São Paulo.

In the public health system, any interpretation of the official data regarding hospital fatality due to AMI requires caution. The increase observed from 1985 to 1988 may have been artificial, caused by the possibly inflated number of hospital admissions in 1984 (14,560 hospital admissions due to AMI, a figure $41.6 \%$ higher than the 10,285 hospital admissions in 1988). The numbers from 1989 to 1998 seem more reliable and, if true, they show a significant drop in

\begin{tabular}{|c|c|c|c|}
\hline Year & $\begin{array}{l}\text { Deaths due to AMI in public } \\
\text { health system hospitals }\end{array}$ & $\begin{array}{l}\text { Hospital admissions due to AMI } \\
\text { in the public health system }\end{array}$ & $\begin{array}{l}\text { Hospital fatality* due to AMI } \\
\text { in the public health system }\end{array}$ \\
\hline 1984 & 1805 & 14560 & 12.4 \\
\hline 1985 & 1728 & 10292 & 16.8 \\
\hline 1986 & 1644 & 8965 & 18.3 \\
\hline 1987 & 1827 & 9497 & 19.2 \\
\hline 1988 & 2175 & 10285 & 21.1 \\
\hline 1989 & 2171 & 10610 & 20.5 \\
\hline 1990 & 1985 & 10241 & 19.4 \\
\hline 1991 & 2137 & 12811 & 16.7 \\
\hline 1992 & 2075 & 13186 & 15.7 \\
\hline 1993 & 2083 & 13049 & 16.0 \\
\hline 1994 & 1969 & 12316 & 16.0 \\
\hline 1995 & 1809 & 11363 & 15.9 \\
\hline 1996 & 1675 & 9906 & 16.9 \\
\hline 1997 & 1641 & 9587 & 17.1 \\
\hline 1998 & 1775 & 10428 & 17.0 \\
\hline
\end{tabular}


fatality from 1989 to 1992 (from $20.5 \%$ to $15.7 \%$ ) and a slight increase from 1993 to 1998 (from $16.0 \%$ to $17.0 \%$ ).

Based on this last observation it can be said that patients with AMI arriving at public health system hospitals in the state of São Paulo from 1993 to 1998 did not benefit more than those arriving in 1992. Our hospital fatality statistics of more recent years are far higher than the $11.8 \%$ (in 1990) of a service in Sweden ${ }^{6}$ and the $9 \%$ (in 1992) of the city of Hamilton, in Canada ${ }^{7}$. On the other hand, they are close to the $16.3 \%$ (in 1991) of the Canadian province of Ontario ${ }^{8}$ and lower than the $20.2 \%$ (in 1991) in a British health district ${ }^{9}$.

Considering that hospital fatality due to AMI in the public health system has not decreased in the recent years, the marked reduction in in-hospital deaths due to AMI from 1993 to 1997 might have resulted from the decrease in hospital admissions due to AMI in the public health system.
The reduced and declining contribution of the public health system to the total of hospital deaths due to AMI diminishes the importance we thought this public health system had in the hospital network of the state of São Paulo as a whole. The authors were surprised to verify that in 1984 less than $23 \%$ of the in-hospital deaths due to AMI occurred in the public health system, and this percentage decreased to $13.7 \%$ in 1996 . Therefore, at least regarding this cause of hospital admission and death, a more comprehensive system of information is required (processing of the CAH106 reports) to provide data on what is really happening with hospital deaths due to AMI. Death due to AMI, as is already known, has been decreasing in various parts of the world according to population-based studies ${ }^{4,6-10}$.

Data used in this study, even though secondary, are official.

\section{References}

1. Marcopito LF, Shirassu MM. Mortalidade por infarto agudo do miocárdio e pelas demais doenças isquêmicas do coração no Estado de São Paulo, 1980-1996. Arq Bras Cardiol, 2000 (in press).

2. Uemura K, Pisa Z. Trends in cardiovascular disease mortality in industrialised countries since 1950. World Health Statist Q 1988; 41: 155-78.

3. McGovern PG, Pankow JS, Shahar E, et al. Recent trends in acute coronary heart disease: mortality, morbidity, medical care, and risk factors. The Minnesota Heart Survey Investigators. N Engl J Med 1996; 334: 884-90.

4. Bata IR, Eastwood BJ, Gregor RD, et al. Decreasing mortality from acute myocardial infarctions: effect of attack rates and case severity. J Clin Epidemiol 1997; 50:787-91.

5. Rosamond WD, Chambless LE, Folsom AR, Cooper LS, Conwill DE, Clegg L, Wang CH, Heiss G. Trends in the incidence of myocardial infarction and in mortality due to coronary heart disease, 1987 to 1994. N Engl J Med 1998; 339: 861-7.

6. Dellborg M, Eriksson P, Riha M, Swedberg K. Declining hospital mortality in acute myocardial infarction. Eur Heart J 1994; 15: 5-9.

7. Le Feuvre CA, Connoly SJ, Cairns JA, Gent M, Roberts RS. Comparison of mortality from acute mayocardial infarction between 1979 and 1992 in a geographically defined stable population. Am J Cardiol 1996; 78: 1345-9.

8. Naylor CD, Chen E. Population-wide mortality trends among patients hospita- lized for acute myocardial infarction: the Ontario experience, 1981 to 1991. J Am Coll Cardiol 1994; 24:1431-8.

9. Greenbaum RA, Morris R, Sritara P, Shanit D, Chan KL. Reduced in-hospital mortality from acute myocardial infarction with general adoption of thrombolytic treatment in the North West Thames health region 1979-1991. Br Heart J 1995; 74: 493-6.

10. Ohara $\mathrm{D}, \mathrm{McD}$ onald I. Trends in in-hospital mortality following acute myocardial infarction(AMI) in Victoria, 1987-1994. Aust NZJ Med 1997; 27: 431-6.

11. OrtizLP. Tendências recentes da mortalidade em São Paulo. Informe Demográfico, Fundação SEADE. São Paulo, 1988; 21:.5-46.

12. Datasus, MinistériodaSaúde (http:Ilwww.datasus.gov.br)-InformaçãoDireta, 1999.

13. Organização Mundial da Saúde - Manual da classificação estatística internacional de doenças, lesões e causas de óbitos. Volume I, Centro da OMS para a Classificação de Doenças em Português. São Paulo, 1985: 815.

14. Organização Mundial da Saúde - Classificação estatística internacional de doenças e problemas relacionados à saúde. Volume I, Centro Colaborador da OMS para a Classificação de Doenças em Português. São Paulo, 1993: 1247.

15. Laurenti R, Mello-Jorge MHP. O atestado de óbito. Centro da OMS para a Classificação de Doenças em Português. São Paulo, 1996: 90.

16. National Center for Health Statistics - Advanced report of final mortality statistics. USPHS, DHHS 1982; 85: 1120. 